\title{
Student use of mobile devices in university lectures
}

\author{
Neil Roberts, Michael Rees \\ Bond University, Australia
}

\begin{abstract}
Mobile devices are increasingly used by students in university lectures. This has resulted in controversy and the banning of mobile devices in some lectures. Although there has been some research into how students use laptop computers in lectures, there has been little investigation into the wider use of mobile devices. This study was designed to investigate which mobile devices students use, what they use them for and the duration of each activity within 1 hour lectures. Students in six cross faculty core classes ( $n=74$ students total) at Bond University responded to a survey asking them to document and comment on their mobile device use over the previous hour at the end of their lecture. A focus group of students who had not been surveyed was conducted to cross-validate the survey results. The key results were that $66 \%$ of students responding to the survey reported using a mobile device in the lecture. Of this group, $45 \%$ used a mobile phone and $38 \%$ a laptop. The most common activity was typing notes on a laptop, followed by accessing lecture slides. The vast majority of mobile device usage was on task and related to the lecture.
\end{abstract}

\section{Introduction}

In society today, mobile devices are pervasive in all aspects of daily life at home, for leisure, during study and at work. These devices exist in an ever-widening range of computer hardware types and include smartphones, tablets, netbooks, and laptops. These mobile devices are now regarded as essential learning tools (Traxler, 2010). It is therefore unsurprising to see them proliferate in the higher education student population. At universities, $87 \%$ of students own laptops, more than half have a smartphone, and $8 \%$ own an iPad (Dahlstrom, de Boor, Grunwald, \& Vockley, 2011). Kinash, Brand, Mathew and Kordyban (2011) found that $48 \%$ of students brought their laptops to lectures, while according to Abilene Christian University (2011), 89\% of students brought a mobile device to class. The current generation of students are "accustomed to operating in a digital environment for communication, information gathering and analysis", tend to be "always on" (Oblinger, 2004, p. 2) and are focussed on connectedness and social interaction. They tend to multitask and, according to McMahon and Pospisil (2005), they have "lots of things 'on the go' at once" (p. 425).

This rise in popularity of mobile devices has led some lecturers and universities to ban them in lectures, because of the wide range of distractions that they give students access to (Baron, 2013; Conway, 2013). The use of mobile devices in lectures is changing rapidly, and although there are some reports of how students are using their laptops in lectures (e.g. Fried, 2008; Lauricella \& Kay, 2010) little attention has been paid to the specific actions that students undertake with other mobile devices such as iPads and mobile phones during a lecture. Since a major reason that these devices have been banned in lectures is that it is believed they are being used for off task activities, it is important to have a clear understanding of what students use them for.

This paper investigates what mobile devices students use, what they use them for and the duration of each activity within 1 hour lectures.

\section{Background}

Mobile devices offer many advantages to students at university (Annan-Coultas, 2006), enabling them to take and edit notes neatly, as well as to organise and structure notes effectively without messy paper handling (Murray, 2011). Another significant benefit of electronic notes is the ability to search for concepts and to redefine the structure and note order (Weaver \& Nilson, 2005). Notes documents can also be shared and synchronised with other mobile devices so that they can be accessed anywhere (Schepman, Rodway, Beattie, \& Lambert, 2012). Furthermore, students can access instructor-provided class materials instantly and search and access public multimedia and other material online (Hall \& Elliott, 2003). McCreary (2009), for example, found that $77.8 \%$ of law students surveyed went online to look up cases, statutes or lecture-related material. Mobile devices can also be used to provide immediate response to the 
lecturer through a Twitter feed (Young, 2010) or the use of real-time online poll apps (Law, 2012). Feedback from student focus groups by Kinash, Brand and Mathew (2012) indicated that students found learning resources on iPads efficient, engaging and interactive, and commented on the portability and lower environmental impact as compared to bound textbooks, paper and pen.

Despite these advantages, there is some opposition to student use of mobile devices in lectures (Maxwell, 2007; Yamamoto, 2008) due to issues with distractions, note taking and lack of discussion in lectures, among others (Murray, 2011). Consequently, some classes and university authorities are using bans and 'Internet kill' switches to prevent laptop usage (Foster, 2008; Luther, 2012).

One commonly cited reason for opposition is the potential for distraction (Colb, 2006; Murray, 2011). Mobile devices enable students to access games, social media, email and chat, as well as to watch movies, shop and surf the internet, among others. These diversions are not only distracting for the student who is using the mobile device, but also for other surrounding students (Yamamoto, 2008). Distractions such as the noise of typing or a colourful light-emitting screen can also affect nearby students, and many lecturers have made reference to the sense of disconnection of students using laptops (Maxwell, 2007; McCreary, 2009; Yamamoto, 2008). Some lecturers request laptop users to sit near the front (Young, 2006) or near the back (McCreary, 2009) of the lecture room to decrease distraction to themselves and other students. However, it has been argued that distractions in lectures are nothing new, and unrelated multitasking can be compared with traditional low tech distractions such as doodling or note passing (Hembrooke \& Gay, 2003; Lauricella \& Kay, 2010). Conversely, Maxwell (2007) points out that few lecturers would allow students to openly read a newspaper or play solitaire on the desk in front of them, and the nature of the distraction of mobile devices is far greater, which leads to a decrease in student engagement in the classroom.

Traxler (2010) stated that there is another side to disruption, and that mobile devices "allow students to access and store images and information of their own choosing and perhaps create and distribute new images and information independently of the lecturers and of the university" (p.157). In other words, rather than characterising student use of mobile devices as distraction, Traxler wrote that student-centred flexible use of learning resources through mobile devices means that the university and lecturer are no longer the gatekeepers of information.

The literature suggests that laptops tend to be used for polarised tasks, "either to assist the student to follow the class, or to engage in a task unrelated to the class" (Barkhuus, 2003, p.4). In research conducted by Kinash, Brand, Mathew and Kordyban (2011), for example, half the students who took their laptops to lectures reported that they used their device primarily to access the learning management system (Blackboard) for the subject. Half the students stated that they went on Facebook, a third stated that they accessed Wikipedia and a third texted during the lecture. Similarly, in a survey on laptop use in lectures among law students (McCreary, 2009), 96.1\% of participants reported that they used their laptops to take notes. However, at the same time, $70.5 \%$ reported that they surfed the web during the class, and $14.5 \%$ used their laptops to play games.

It would also appear that multitasking during lectures is common (Gay \& Grace-Martin, 2001; Hembrooke \& Gay, 2003). Fried (2008), for example, found that students with laptops used them during $48.7 \%$ of the lecture time. Over this period they multitasked for an average of 17 minutes of each 75 minute lecture. This included checking email (81\%), using instant messaging (68\%), surfing the web $(43 \%)$, playing games (25\%) and other activities (35\%). Similarly, Kraushaar and Novak (2006) used analysis of voluntary installation of monitoring software on student computers and found that of every 100 productive windows open, students opened 33 distractive windows related to surfing and entertainment, 27 windows related to email, and 43 related to instant messaging. They found that students multi-tasked heavily using laptops, and actively used non course-related software applications for approximately $42 \%$ of the lecture. In another study, McCreary (2009) found that $38.4 \%$ of law students used instant messaging during lectures, and $42.1 \%$ went on line for general surfing, such as shopping.

In terms of mobile phone usage and tablet use in lectures, relatively little has been researched as to how they are used. Mobile phones are extremely common in lectures. Kinash, Brand, Mathew and Kordyban (2011) for example, found that $96 \%$ of students brought their mobile phone to class and that students used mobile phones and laptops equally during lectures. However, mobile phones appear to be used mainly for 
off task activities with students reporting that $80 \%$ of mobile use was dedicated to social networking, $75 \%$ for web browsing and 68\% for email (Kinash et al., 2011). Similarly, research conducted by Smith, Salaway and Borreson Caruso (2009) revealed that $32 \%$ of students used their mobile phone or handheld device for non-course activities, as opposed to $11.3 \%$ for course-related activities, and found that checking news, weather and sports were the most common activities (76\%). Results of a student survey by Katz (2005) showed that $41 \%$ of students had used their phones to check messages and $34 \%$ to be distracted from a boring class. Fifty per cent of students in Katz's research reported that they found the phone distracting.

Tablets, on the other hand, tend to be less commonly used than laptops, and Kinash et al. (2011) found only a small percentage (4\%) of students used a tablet computer in class. Like mobile phones, they would also appear to be used more for off task activities. Kinash, Brand and Mathew (2012) found that the main use for iPads during lectures was surfing the web for pleasure, using Facebook, and the lowest use was for taking notes in class.

This paper sets out to discover in more depth the specific activities for which students used their mobile devices in lectures. Three research questions were asked:

R1. For what purposes did students use their mobile devices in lectures?

R2. How long did students spend using their mobile devices on each activity?

R3. Were the activities more on task or off task?

\section{Methodology}

The sample consisted of a survey of 99 students at Bond University taking core (introductory) subjects. As wide a range of introductory subjects as possible were included in the research so as to eliminate any bias between the disciplines being studied by the students. The core subjects at the university were chosen as suitable for research as they represent a broad population of students across the different disciplines and a cross spectrum of lectures featuring relatively large classes with a variety of teaching styles. These core subjects are compulsory subjects for students studying an undergraduate degree, and are also offered as an elective subject for post graduate students. There are 10 core subjects, which relate to different disciplines. However, mobile devices have been banned in the 4 humanities faculty core subject classes. Among the reasons given were that laptops are not relevant for these subjects, and created distractions both for the user and for other students. As one lecturer put it: "Laptops are banned in my class because the overwhelming majority of the time they are a distraction rather than an aid". Consequently, these classes were not surveyed since no mobile devices were allowed to be used during these lectures.

The remaining 6 core subject classes were surveyed: Strategic Management (Business), Business Applications in IT (Business), Contemporary Issues in Law and Society (Law), Knowledge and Society (Business), Entrepreneurship (Business), and Scientific Thinking (Health Sciences and Medicine).

A cross-sectional retrospective study was used to provide a snapshot of typical mobile device use in a particular 1 hour period. This provided a relatively easy and fast way to look at participants at one point in time (Mann, 2003). Students were asked at the end of the lecture to complete a questionnaire and to indicate which mobile devices they had used in the preceding 1 hour of the lecture, how long they spent using that device and for what activities they had used the device. A research assistant delivered the instructions to the class in order to reduce any bias from the researcher. To ensure that their answers were not influenced, the students were informed that their answers would be anonymous and that the lecturer would not see their completed questionnaires. The survey was optional, and not all students chose to complete the survey. The survey took between 5 and 10 minutes for students to complete.

The survey items were based on a pilot observation of a lecture, and Lauricella and Kay's Laptop Effectiveness Scale (LES) $(2009,2010)$. In order to see the different ways that students used mobile devices in class, an observation was first carried out in a sample lecture. A pilot class was observed and two students were watched to see the different ways that they used their laptops during the 2 hour lecture. 
The observer sat behind these students and annotated the different activities that were undertaken. This observation provided examples of typical student uses of mobile devices to add to the survey.

Lauricella and Kays' LES $(2009,2010)$ was also used as a further source of activities that students typically engage in using a laptop. These activities were chosen based on a literature review of the most salient features of laptop usage, and consisted of four constructs: academic, class use; communication; watching movies; and playing games (Lauricella \& Kay, 2010). An example question from the LES is "How much of the lecture time in this course do you use the laptop to take notes or follow the lecture?"

A paper based survey was chosen since it was important for students to complete the questionnaire immediately at the end of the lecture. An online survey would have meant that students would complete this sometime after the lecture, by which time they may have forgotten how they had used mobile devices. Furthermore, some students do not bring mobile devices to class, so would not be able to complete an online survey in the lecture. In addition, according to Nulty (2008), "online surveys are much less likely to achieve response rates as high as surveys administered on paper" (p.2). A copy of the survey is available from the first author upon request. The raw data was collected from the paper based survey, and SPSS was used to calculate the mean for the overall usage of the group. To obtain a figure of the actual time spent on specific activities, further calculations were made to create means for students who had used a mobile device for a specific activity.

A follow-up student focus group of 1 hour was held to discuss the results of the questionnaire. The students were recruited via an all student email, and were given cinema tickets as an incentive. These students were independent of the original cohort that were surveyed, and a research assistant facilitated the session so as not to confound or influence their contributions. The focus group students were asked to discuss their own use of mobile devices in lectures and to comment on the results from the survey (see Appendix B). The discussion was recorded and then transcribed. Relevant comments and points were then summarised.

\section{Results}

This section examines the results collected from the survey of the students at the end of the lectures, as well as the focus group responses to this data. It was found that the majority of the time spent on mobile devices was related to course work and was on task, with the exception of the phone, which tended to be used for off task activities.

\section{Response rate}

Of the 99 students who completed the survey questionnaire, 25 did not report how long they spent using a mobile device, but simply ticked the box instead. Their data were therefore not included in the study. This brought the valid sample down to 74 . Of these, $62 \%$ were aged $17-21(n=46), 23 \%$ were $22-26(n=$ $17), 3 \%$ were $27-31(n=2)$ and $11 \%$ were above $31(n=9)$. All but one were undergraduate students. The participants came from the following subjects: Strategic Management (5.4\%), Business Applications in IT (18.9\%), Contemporary Issues in Law and Society (25.7\%), Knowledge and Society (9.5\%), Entrepreneurship (20.3\%), and Scientific Thinking (20.3\%).

The follow-up student focus group consisted of 6 undergraduates and 7 postgraduates $(n=13), 6$ of whom were domestic students and 7 international. This group was independent of the original students that were surveyed and came from 3 different faculties: Humanities and Social Sciences $(n=6)$, Law $(n=6)$, and Business (1). 


\section{Usage of mobile devices}

The majority of students used a mobile device of some kind during the lecture $(66.2 \%, \mathrm{n}=49)$. Those who did not use a mobile device $(n=25)$ gave various reasons for this:

- $\quad$ they were too busy taking notes and listening to the lecture (3),

- $\quad$ they preferred to hand write notes (4),

- $\quad$ it was distracting and prevented them from learning (3),

- $\quad$ it was rude (2),

- $\quad$ they were having technology problems (2),

- it was unnecessary (1),

- $\quad$ no reason given (10).

As shown in Figure 1, the most commonly used device was a mobile phone $(n=33)$, followed by a laptop $(n=28)$. Tablets were less common, with 7 students reporting using an iPad2, while iPad 1 and netbooks were only used by 3 students. The focus group reported an even higher usage of mobile devices, with 11 of the 13 students saying that they used a mobile device during lectures $(85 \%)$. The remaining 2 students stated that they prefer to hand write notes.

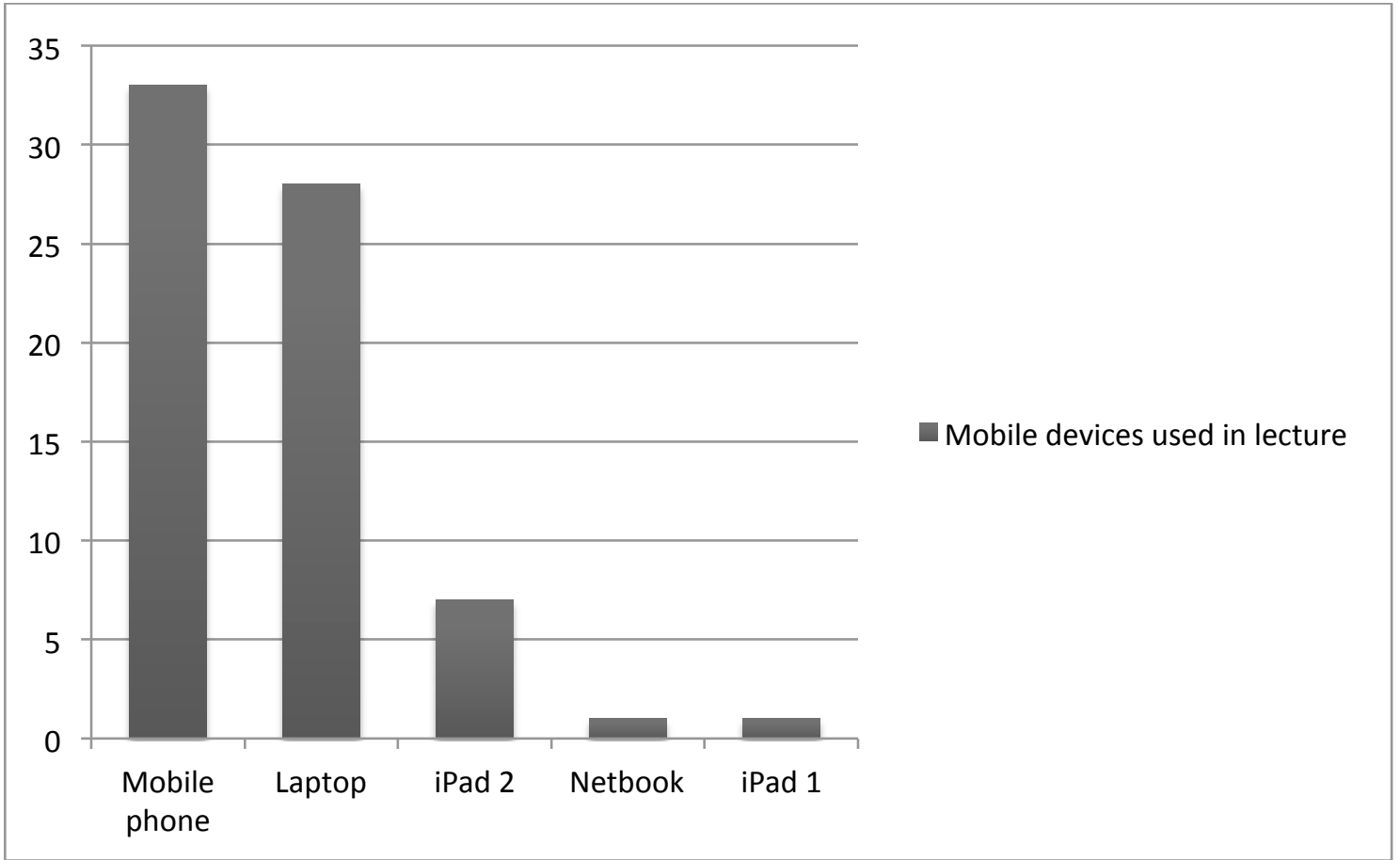

Figure 1. Distribution of mobile devices used in lecture.

\section{Student activities and time spent on laptops}

As shown in Figure 2, by far the most common overall mean activity during the lecture was taking notes on a laptop (20 students). The other main use for laptops was for lecture research (18 students) followed by accessing lecture slides (16 students). Eleven students checked their email, while 9 students used Facebook, and 8 students used their laptop for pleasure to surf the internet. Eight students did unrelated research using their laptop while 2 students played games. 


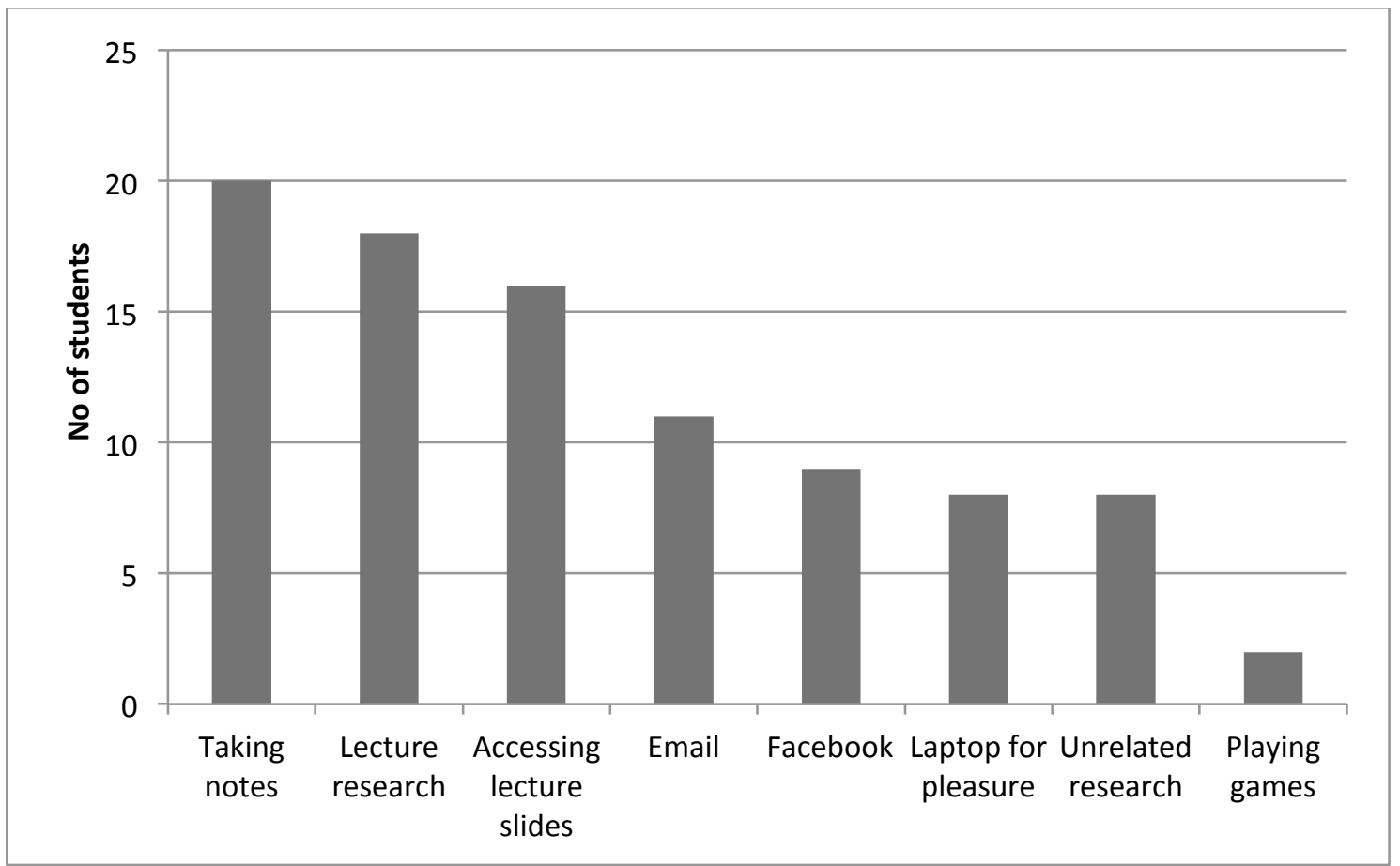

Figure 2. Number of students per activity.

The total time spent completing on task activities (taking notes, lecture research and accessing lecture slides) was 1792 minutes. The total time spent doing off task activities (unrelated research, surfing the internet for pleasure, Facebook, email and games) was 746 minutes.

Figure 3 shows the actual time of use per activity by students who used a mobile device. The activity that students spent the most time on was taking notes, and an average of 45.3 minutes was spent accessing lecture slides. Lecture research was also a popular activity and the 18 students who used a laptop for lecture research spent an average of 21.7 minutes on this task.

In terms of off task activities, 2 students spent an average of 40 minutes playing games with one student spending 20 minutes doing this, while the other spent 60 minutes. However, this skews the results in Figure 3 as it shows as the second longest activity for students due to the very small sample size $(n=2)$. In addition, students spent an average of 25.25 minutes surfing the internet, 19.6 minutes on unrelated research, and 18 minutes on Facebook. The least amount of time was spent writing and checking email (14.7 minutes).

\section{Student activities and time spent on iPads}

The next most common device used was the iPad 2. The iPad 1 was only used by 1 student, who did not use the device during the lecture. Figure 4 summarises the activities and number of students who used an iPad 2 during the one-hour lecture. This was predominantly used to access lecture slides (6 students) and undertake related research to the lecture (6 students). An average of 37.5 minutes was spent on accessing lecture slides, while 23.3 minutes was spent on lecture research. 3 students used iPad 2 to take notes, spending an average of 26.6 minutes on this activity. In terms of off task activities, 5 students reported using the iPad 2 for unrelated research, which amounted to an average of 20 minutes, while 3 students used the iPad to briefly surf the internet for pleasure (average 3 minutes). 1 student reported using Facebook for 30 minutes, while another reported writing email for 60 minutes.

The total time spent doing on task activities was 445 minutes, whereas the total time for off task activities was 53 minutes. This amounts to a mean of 29.6 minutes for on task activities against 6.6 minutes for off task activities per student. 


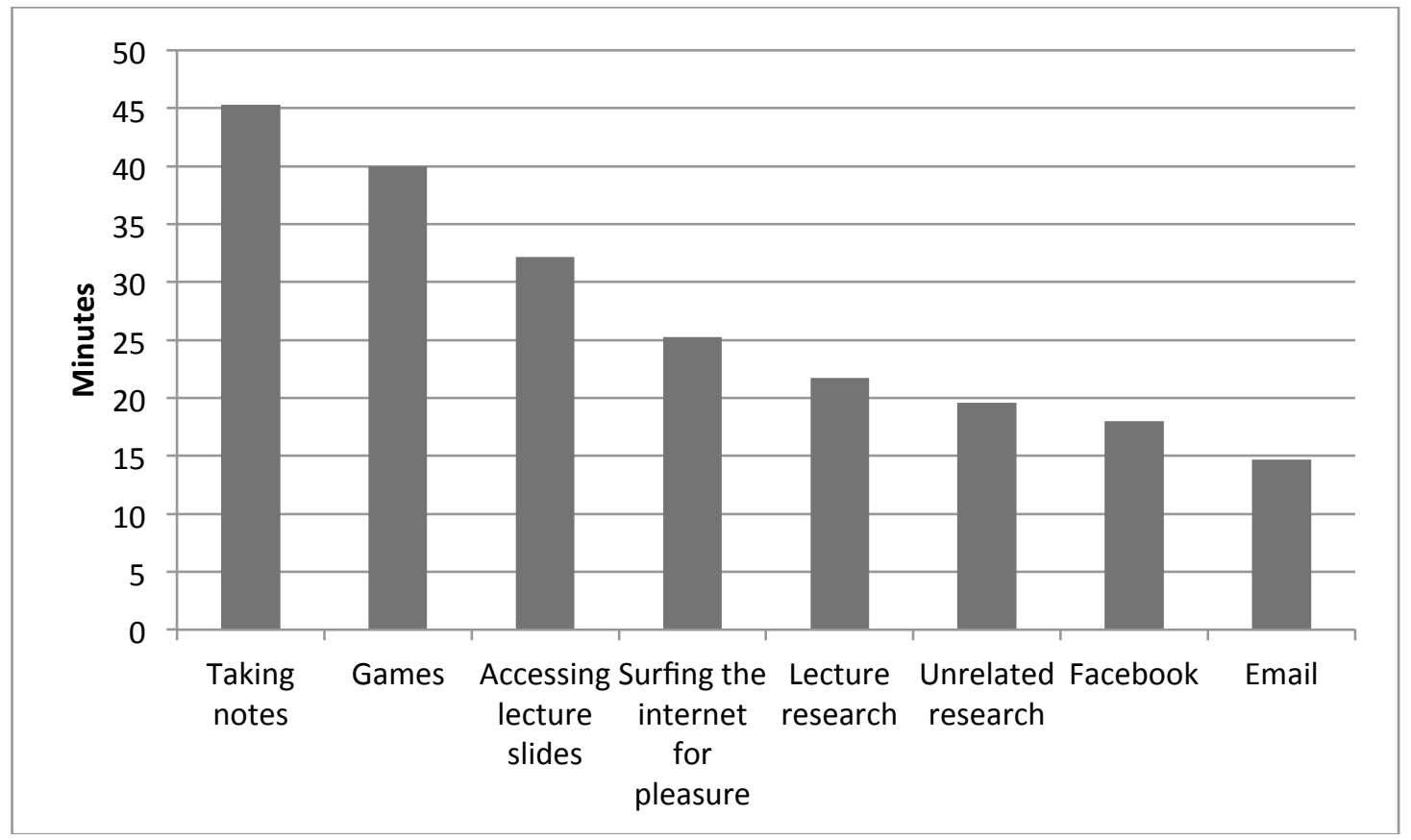

Figure 3. Time and activity by students who used a laptop.

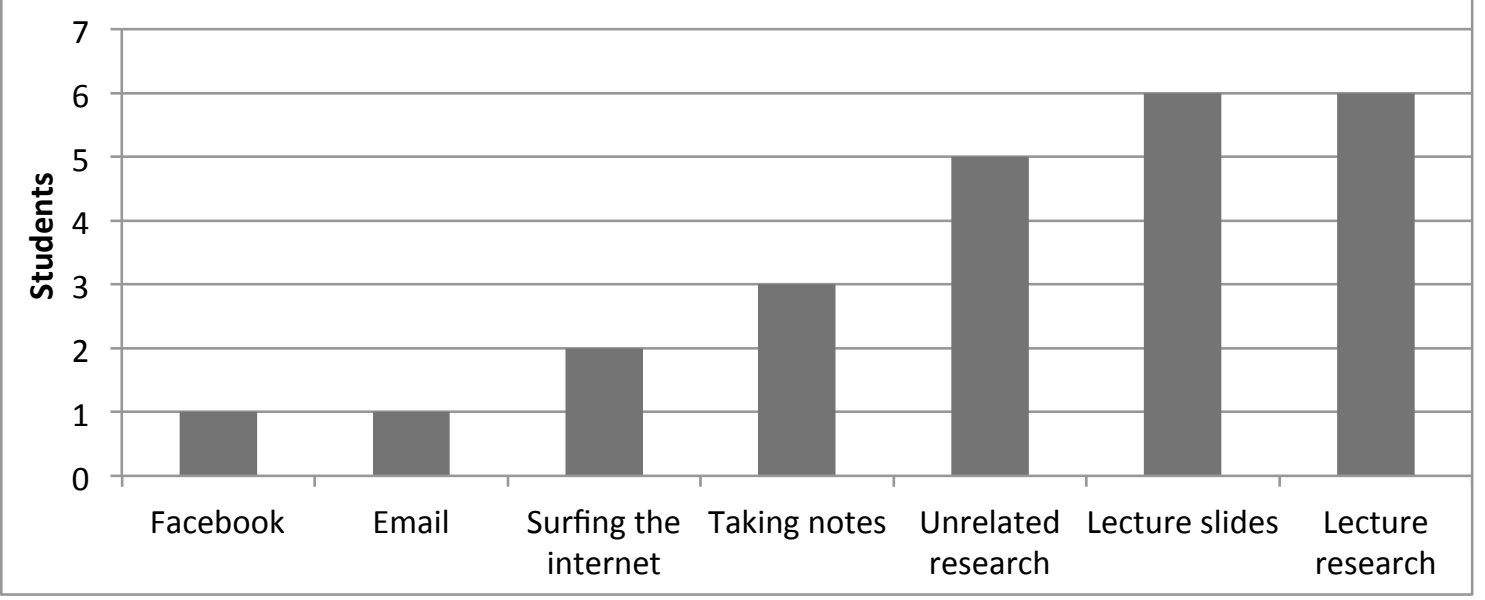

Figure 4. Number of students and activities who used an iPad.

\section{Student activities and time spent using mobile phones}

Mobile phones were used to a lesser extent than the other devices. As Figure 5 shows, these were mainly used for texting $(n=23)$ and those that reported using a mobile phone for this activity spent an average of 6 minutes on this during the lecture. The next most common use of mobile phones was for Facebook $(\mathrm{n}=7)$, and students spent an average of 10 minutes on this. Four students used their phone for checking email; however, this tended to be brief, with an average of 2.5 minutes. Although only 2 students reported using their phone for chatting, this tended to be much longer, with a mean of 37.5 minutes. Other uses included unrelated research $(2$ students), surfing the internet for pleasure ( 2 students) and related lecture research (1 student). No students reported using the phone for accessing the slides in the lectures and only 
1 reported using it for taking notes. However, it was pointed out in the focus group that another common activity in lectures was to use the phone to take photos of lecturers' PowerPoint screens or whiteboards.

Students used their mobile phones more for off task activities (total of 337 minutes) than for on task activities (total of 67 minutes). However, since the off task activities were brief, the average time spent undertaking on task activities $($ mean $=16.8)$ was higher than for off task activities $($ mean $=8.8)$.

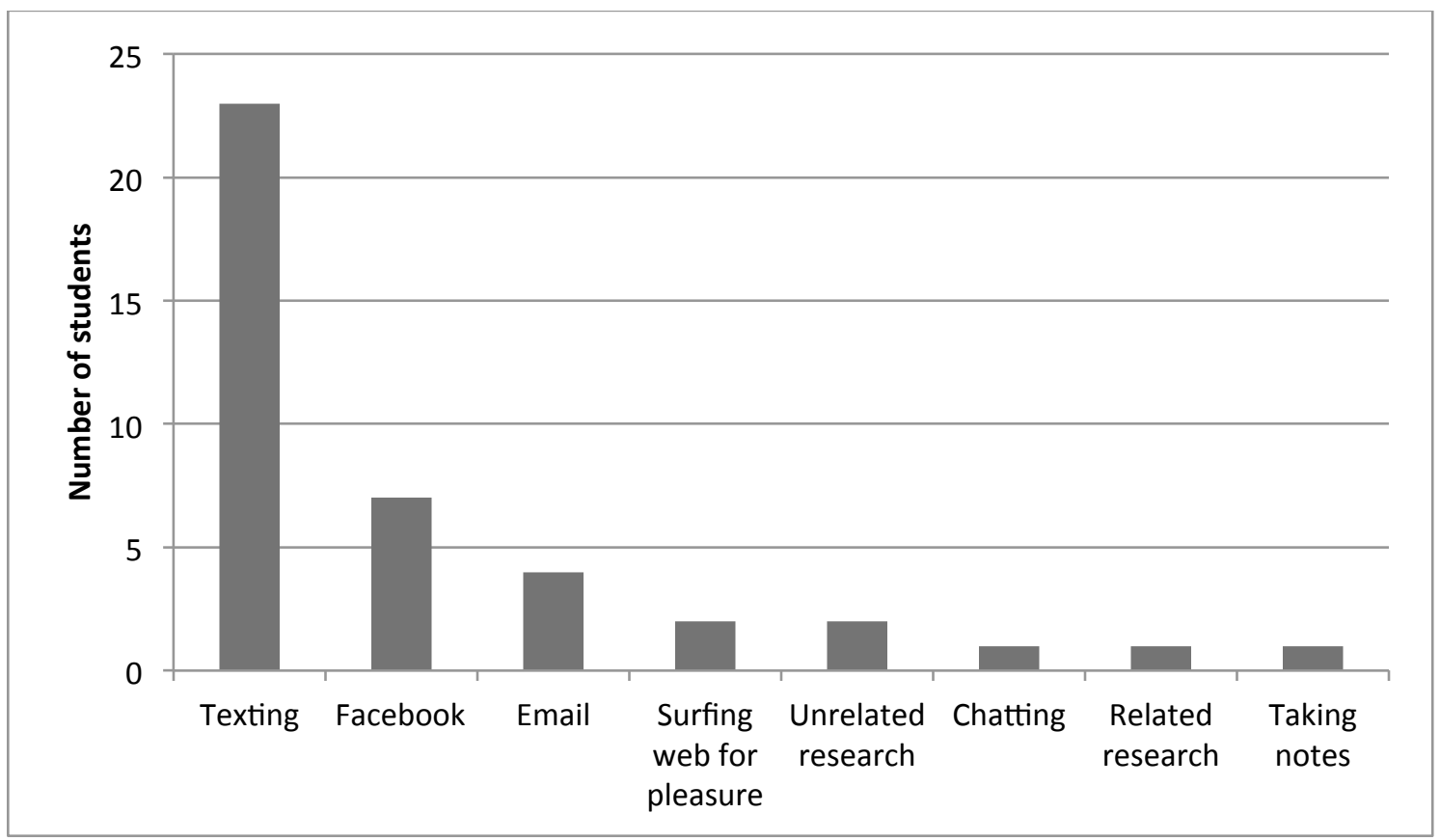

Figure 5. Number of students and activities spent on mobile phones.

\section{Other Results}

Twitter was not used by any students during the lectures. Only 2 students reported accessing games, although one of these students spent 60 minutes on this activity. Seven students used an online dictionary, 2 of whom were non-native speakers.

\section{Discussion}

Although overall mobile device usage during the lectures was relatively high, it was $22.8 \%$ lower than found at Abilene Christian University (2011). The majority of the focus group felt the number of students who did not use a mobile device was "unsurprising" or "normal" and was an indicative number, although one student did comment that "24 seemed a lot". In terms of the reasons given by the students in the research survey for not using a mobile device, the focus group commented that there was "nothing surprising". They did feel, however, that using a mobile device in class was not rude, as long as it was being used for educational purposes. They also pointed out that mobile phone usage depended on age ("a lot of the older students don't use a laptop") and subject ("it depends on what degree you're in ... 90\% of the students in law come to class with a laptop"). One international student also said that many overseas students do not have access to wifi at home, and take advantage of the wifi at university to "do all the things they have to do."

In terms of mobile phone use, although the participants reported the mobile phone as the most commonlyused device, only a small number of students actually reported using them in the survey. The follow up focus group hypothesised that the time spent using mobile phones was high since students were "quickly checking" the devices for the time, messages or missed calls as opposed to using the devices for extended periods of time and therefore may not have considered this worthy of mention in the survey. They also pointed out that it was difficult to say what counts as usage ("Does checking the time mean I'm using the 
phone? There are seven mobile phones on the table right now, does that mean that counts as being used?") Students in the focus group reported that their own mobile phone usage was predominantly for texts, emails and Facebook, although one student reported using it for recording lectures. This is consistent with findings by Kinash et al. (2011), who also found that mobile phone usage was predominantly for off task activities.

Regarding what kinds of mobile devices are used in class, laptops were found to be the most commonly used device. This is consistent with Dahlstrom et al. (2011), who found that the laptop was rated by students as the most valuable device for academic success $(81 \%)$. iPads, on the other hand, were rated low $(24 \%)$ by students on this scale in terms of value to academic success (Dahlstrom et al., 2011).

A key question raised in this research was what activities students engaged in, and to what extent they were on or off task. There appeared to be more on task activities than off task, and the majority of mobile device usage tended to be on task. However, the focus group commented that the amount of time reported on Facebook and emailing using mobile phones was surprisingly low and not indicative of what happens regularly in lectures in their view ("Facebook should be off the chart"). The focus group also considered the use of laptops for unrelated research to be "surprisingly high" and stated that research for other subjects is not usually done in lectures unless students are panicking about an assignment due to be submitted. The low usage of Twitter was also similar to findings by Perez-Carballo and Blaszcynski (2011), who found that $72 \%$ of students had never used Twitter.

Most off task activities seemed to be brief, although one student did play games, watched unrelated YouTube videos, chatted and surfed the web for the entire hour. Off task behaviour was particularly noticeable with mobile phones, which tended to be used more for off task research activities rather than on task.

Overall, iPad use was found to be on task. This was inconsistent with Kinash et al. (2011) who found that students felt that "the iPad was a novelty, but not a valid educational tool" (p.6). This could be because the novelty value of an iPad has worn off since this study, and iPads have become more mainstream. The iPad2 was not used a great deal for taking notes, which was consistent with Kinash, Brand and Mathew (2012). Similarly, none of the students in the focus group reported using the iPad2 for note taking. One possible reason for this could be that the touch keypad is still a new idea that users are becoming accustomed to, or that it is less easy to use. It could also be because laptops are perceived as superior for taking notes. As Traxler (2010, p.151) points out, users prefer "specialised dedicated devices rather than any generic and more general-purpose device".

In many cases, the total time that students spent on various activities added up to far more than an hour, which suggests that they multitasked frequently. This raises the question: to what extent does multitasking affect performance in class? According to Rekart (2011), "dividing attention by multitasking impedes learning and performance in the short-term and may, by underutilizing brain structures necessary for the correct type of learning, affect long term memory and retention" (p.61). Similarly, Wood et al. (2011) found that students who did not use mobile devices in lectures out performed students who used technology. One student in the focus group commented that even though she used a mobile device during lectures, she would "pay attention better" and wouldn't "have all these distractions" if she did not use the technology.

The study had a number of limitations. As Shiffman, Stone and Hufford (2008, p.7) point out, recall, even when recalling the past hour, is "fraught with systemic memory bias", and it is possible that the students over or underestimated their usage at the end of the hour. It is also possible that students lowered the time spent on off task activities, even though the survey was anonymous and would not be read by the lecturer. Digit bias (Shiffman, 2009), whereby participants round up the figures, may also have affected the results in terms of the times spent on an activity. In addition, although the survey asked students to write down the time spent on an activity, some students only ticked a box and had to be discounted from the data. To avoid this in any future replication of this study, it would be recommended to present the students with a selection of times from which to choose. It is recommended that future replication of the survey be done online and mid lecture using a selection of multiple choice times to avoid these problems. 
One participant commented "what is a mobile device?", suggesting that there could be some confusion with the term and that some students may have overstated their use of a mobile phone at the beginning of the survey, thinking that this meant mobile device. This could also explain why mobile phone usage was reported to be higher than laptop use, yet laptops accounted for most usage. There might also have been some confusion with the term 'netbook', as this could have been construed to be a small laptop or an Android tablet. Another area that may have affected the data is the term chatting. Students may have interpreted this as texting, instant messaging or talking on the phone. All of these problems of exact nomenclature should be carefully addressed in the design of future questionnaires. In addition, student mobile use could have been affected by the nature of the lecture and lecturer's approach to mobile devices.

In terms of the response rate, the survey was voluntary and held at the end of the lecture. As a result, many of the students left the room before completing the survey; therefore, the sample was not a true cross section of all the students in this class. It is possible that the results would have been different had all the students been surveyed, as the views of the disinterested students would have been obtained as well. Furthermore, students who did not use a mobile device may not have completed the survey since they thought it was not relevant to them.

\section{Conclusion}

This study set out to determine how students used mobile devices in lectures, the time spent on activities over a 1 hour class, and to what extent these activities were on or off task via a cross-sectional retrospective survey. The main activity that students spent the most time on was found to be taking notes and accessing lecture slides, suggesting that overall mobile device behaviour in the lectures tended to be more on task than off task. However, during the lecture, students tended to multitask and not focus on just one activity. The findings of this study indicate that since the majority of mobile device usage is on task, a ban on their usage in lectures is perhaps draconian, although the study does support the claim that students who use mobile devices do multitask.

There is a need for further research into several areas. Further cross-faculty studies are needed with larger samples to further support this study. Since note taking is the main activity of students using laptops, more investigation needs to be done into the ways that students are taking notes, and whether they are using transcript style, summarising the main points, using dot form or mind maps. In addition, further investigation into student use of note taking applications such as Microsoft OneNote, Evernote, and others is necessary. The range of mobile devices is expanding rapidly, and as the software and hardware supporting these devices evolve, student usage and behaviour will adapt and change. Frequent further studies will be needed to keep abreast of these changes and the effectiveness of using mobile devices in learning.

\section{References}

Abilene Christian University. (2011). 2010-11 Mobile learning report. Retrieved from http://www.acu.edu/technology/mobilelearning/documents/ACU_M-_2010-11.pdf

Annan-Coultas, D. (2006). Laptops as instructional tools: Student perceptions. TechTrends, 56 (5), 34-41.

Barkhuus, L. (2003). Bring your own laptops unless you want to follow the lecture. Journal of Computing in Higher Education, 15 (1), 46-64.

Baron, D. (2013, January 14). Banning laptops in the classroom [Web log post]. Retrieved from https://illinois.edu/blog/view/25/87314

Colb, S. F. (2006, September 6). Taking notes without a computer: How laptops distract from classroom learning. Retrieved from http://writ.news.findlaw.com/colb/20060906.html

Conway, M. (2013, February 14). Off of Laptops: On task? Retrieved from http://www.thecrimson.com/article/2013/2/14/laptops-classroom-internet-ban/

Dahlstrom, E., de Boor, T., Grunwald, P., \& Vockley, M. (2011). ECAR: National study of undergraduate students and information technology. Retrieved from http://net.educause.edu/ir/library/pdf/ERS1103/ERS1103W.pdf

Foster, A. (2008). Law professors rule laptops out of order in class. The Chronicle of Higher Education, $54,1-18$.

Fried, C. (2008). In-class laptop use and its effects on student learning. Computers \& Education, 50 (3), 906-914. 
Gay, G., \& Grace-Martin, M. (2001). Wireless web browsing and academic performance. Educause Quarterly, 3, 67.

Hall, M., \& Elliott, K. (2003). Diffusion of technology into the teaching process. Journal of Education for Business, 78 (6), 301-307.

Hembrooke, H., \& Gay, G. (2003). The laptop and the lecture : The effects of multitasking in learning environments. Journal of Computing in Higher Education, 15 (1), 46-64.

Katz, J. E. (2005). Mobile phones in educational settings. In K. Nyiri, A Sense of Place (pp. 304-319). Vienna: Passagen Verlag.

Kinash, S., Brand, J., \& Mathew, T. (2012). Challenging mobile learning discourse through research: Student perceptions of Blackboard Mobile Learn and iPads. Australasian Journal of Educational Technology, 28 (4), 639-655.

Kinash, S., Brand, J., Mathew, T., \& Kordyban, R. (2011). Uncoupling mobility and learning: When one does not guarantee the other. Enhancing Learning Through Technology, 177, 342 - 350.

Kraushaar, J., \& Novak, D. C. (2006). Examining the affects of student multitasking with laptops during the lecture. Journal of Information Systems, 21 (2), 241-252.

Lauricella, S., \& Kay, R. (2009). Appendix A - The Laptop Effectiveness Scale. Retrieved from http://faculty.uoit.ca/kay/papers/les/AppendixA_LES.pdf

Law, R. (2012). Using quick response codes for student interaction during lectures. Proceedings of the 17 th ACM annual conference on innovation and technology in computer science education, Glasgow, p. 401.

Luther, J. (2012, January 27). Laptop bans in class receive mixed reaction. Retrieved from http://www.dukechronicle.com/article/laptop-bans-classes-receive-mixed-reaction

Maxwell, N. (2007). From Facebook to Folsom Prison blues: How banning laptops in the classroom made me a better law teacher. Richnond Journal of Law and Technology, 14 (2), 1-43.

McCreary, J. R. (2009). The laptop-free zone. Valparaiso University Law Review, 43, 1-87.

McMahon, M., \& Pospisil, R. (2005). Laptops for a digital lifestyle: millennial students and wireless mobile technologies. Australasian Society for Computers in Learning in Tertiary Education Conference Proceedings, Brisbane. Retrieved from http://www.ascilite.org.au/conferences/brisbane05/blogs/proceedings/49_McMahon\%20\&\%20Pospisi 1.pdf.

Murray, K. E. (2011). Let them use laptops: Debunking the assumptions underlying the debate over laptops in the classroom. Oklaholma City University Law Review, 36, 185.

Nulty, D. D. (2008). The adequacy of response rates to online and paper surveys: what can be done? Assessment \& Evaluation in Higher Education, 33 (3), 301-314.

Oblinger, D. (2004). The next generation of educational engagement. Journal of Interactive Media in Education, 8, 1-18.

Perez-Carballo, J., \& Blaszcynski, C. (2011). Social media usage by business college students. Allied Academies International Conference proceedings, Las Vegas. Retrieved from http://www.alliedacademies.org/public/proceedings/Proceedings29/AIMS\%20Proceedings\%20Fall\%2 02011.pdf

Rekart, J. L. (2011). Taking on multitasking. Phi Delta Kappan, 93 (4), 60-63.

Schepman, A., Rodway, P., Beattie, C., \& Lambert, J. (2012). An observational study of undergraduate students' adoption of (mobile) note taking software. Computers in Human Behavior, 308-317.

Shiffman, S. (2009). How many cigarettes did you smoke? Assessing cigarette consumption by global report, Time-Line Follow-Back, and ecological momentary assessment. Health Psychology (28), 519526.

Shiffman, S., Stone, A. A., \& Hufford, M. R. (2008). Ecological momentary assessment. Annual Review of Clinical Psychology, 4, 1-32.

Smith, S., Salaway, G., \& Borreson Caruso, J. (2009). The ECAR study of undergraduate students and information technology 2009. Retrieved from http://www.educause.edu/library/resources/ecar-studyundergraduate-students-and-information-technology-2009

Traxler, J. (2010). Students and mobile devices. ALT-J, Research in Learning Technology, 18 (2), 149160.

Weaver, B. E., \& Nilson, L. B. (2005). Laptops in class: What are they good for? What can you do with them? New Directions for Teaching and Learning, 101, 3-14.

Wood, E., Zivcakova, L., Gentile, P., Archer, K., De Pasquale, D., \& Nosko, A. (2011). Examing the impact of off-task multi-tasking with technology on real-time classroom learning. Computers and Education, 58, 365-374. 
Yamamoto, K. (2008). Banning laptops in the classroom: is it worth the hassle? Journal of Legal Education, 57, 1-46.

Young, J. (2006). The fight for classroom attention : professor vs. laptop. Chronicle of Higher Education, $52(39), 27$.

Young, J. (2010). Teaching with Twitter. Chonicle of Higher Education, 56 (March), 9-13.

Corresponding author: Neil Roberts, nroberts@bond.edu.au

Australasian Journal of Educational Technology (C) 2014.

Please cite as: Roberts, N., \& Rees, M. (2014). Student Use of Mobile Devices in University Lectures. Australasian Journal of Educational Technology, 30(4), 415-426. 